\title{
Effects of formaldehyde on the frog's mucociliary epithelium as a surrogate to evaluate air pollution effects on the respiratory epithelium
}

C. Fló-N eyret'1,4,

G. Lorenzi-Filho ${ }^{1,2}$,

M. Macchione ${ }^{1}$,

M.L.B. Garcia ${ }^{3}$ and

P.H.N. Saldiva ${ }^{1}$

\begin{abstract}
${ }^{1}$ Laboratório de Poluição Atmosférica Experimental, Departamento de Patologia,
${ }^{2}$ Disciplina de Pneumologia, Departamento de Cardiopneumologia, and

${ }^{3}$ Serviço de Clínica Geral, Divisão de Clínica M édica, Hospital das Clínicas,

Faculdade de Medicina, U niversidade de São Paulo, São Paulo, SP, Brasil

4Programa de Pós-Graduação em Reabilitação, Universidade Federal de São Paulo, São Paulo, SP, Brasil
\end{abstract}

\section{Correspondence \\ C. Fló-Neyret \\ Departamento de Patologia \\ Faculdade de Medicina, USP \\ Avenida Dr. Arnaldo, 455, S. 1216 \\ 01246-903 São Paulo, SP \\ Brasil \\ E-mail: clauflo@ zipmail.com.br}

Research supported by CNPq, FAPESP, PRONEX and LIMHCFMUSP.

Received July 13, 2000 Accepted February 5, 2001

\section{Abstract}

The increasing use of alcohol as an alternative fuel to gasoline or diesel can increase emission of formaldehyde, an organic gas that is irritant to the mucous membranes. The respiratory system is the major target of air pollutants and its major defense mechanism depends on the continuous activity of the cilia and the resulting constant transportation of mucous secretion. The present study was designed to evaluate the effects of formaldehyde on the ciliated epithelium through a relative large dose range around the threshold limit value adopted by the Brazilian legislation, namely $1.6 \mathrm{ppm}(1.25$ to $5 \mathrm{ppm})$. For this purpose, the isolated frog palate preparation was used as the target of toxic injury. Four groups of frog palates were exposed to diluted Ringer solution (control, $\mathrm{N}=8$ ) and formaldehyde diluted in Ringer solution at three different concentrations $(1.25,2.5$ and $5.0 \mathrm{ppm}, \mathrm{N}=$ 10 for each group). Mucociliary clearance and ciliary beat frequency decreased significantly in contact with formaldehyde at the concentrations of 2.5 and $5.0 \mathrm{ppm}$ after $60 \mathrm{~min}$ of exposure $(\mathrm{P}<0.05)$. We conclude that relatively low concentrations of formaldehyde, which is even below the Brazilian threshold limit value, are sufficient to cause short-term mucociliary impairment.

The increasing use of alcohol as an alternative fuel to gasoline or diesel can increase aldehyde emissions by more than a thousand-fold, although fitting vehicles with catalytic converters has dramatically reduced such emissions (1). In addition, tobacco smoke may contain even ten-fold higher concentrations of aldehydes than automotive emissions (2). Formaldehyde ( $\mathrm{HCHO}$ ) is an organic gas that is irritant to the mucous mem-

\author{
Key words \\ - Mucociliary clearance \\ - Formaldehyde \\ - Air pollution
}

branes. Molecules that contain an aldehyde moiety are by their nature chemically reactive. Through their polarized carbonyl group, aldehydes can participate in various biochemical cellular reactions and influence associated biological functions (3). Aldehydes are often metabolic intermediates and are present in many environments $(3,4)$.

The respiratory system is the major target of air pollutants. Inhaled pollutants enter the 
body through the throat and nasal cavities and pass to the lungs through the trachea. Pollutants are either absorbed into the bloodstream or moved out of the lungs by tiny hair cells called cilia that are continually sweeping mucus up into the throat. The natural defense mechanism of the respiratory mucosa against harmful foreign agents is dependent on the continuous and harmonic activity of the cilia and the resulting constant transportation of mucous secretion (5-9). The composition of the mucus produced by the secretory cells of the mucosa and the deeperlying glands is also of decisive importance for the efficiency of this protective mechanism. The role of the cilia in the respiratory tract is exceedingly important. The bronchial cilia can be effectively paralyzed by inhaled smoke, enhancing the synergistic effects between smoking and air pollutants (10). Inhaled gas pollutants will be removed from the airways for many of the same reasons as particles and droplets. This results in very little of these gases getting to the lungs, but in the airway mucus, and perhaps in the epithelial cells, these chemicals can have considerable effects by destroying the natural defenses of the airways. Most polluting gases are soluble, such as formaldehyde, and are solubilized on the wet surface of the airways (11).

The present study was designed to evaluate the effects of formaldehyde on the ciliated epithelium, through a relative large span of doses around the threshold limit value adopted by the Brazilian legislation, namely $1.6 \mathrm{ppm}$ (1.25 to $5 \mathrm{ppm})$. For this purpose, the isolated frog palate preparation was used as the target of toxic injury (12). A shortterm toxicity assay (60 $\mathrm{min} /$ dose) was developed and ciliary beat frequency (CBF) and mucociliary clearance (MC) rate were determined as estimators of toxicity.

Mature frogs (Rana catesbeiana) were sacrificed by decapitation. The jaw was disarticulated and the upper portion of the head was removed by cutting it with scissors from the junction of the posterior pharynx and esophagus out to the skin of the back. The frog palate was kept in a refrigerator at $10^{\circ} \mathrm{C}$ for 2 days covered with plastic wrap in a humidified chamber to deplete the palate mucus. On the third day, mucus samples were collected with a needle from the posterior edge of the palate and immediately immersed in mineral oil to prevent dehydration. All the experiments were performed on the third day after frog palate removal. Under these experimental conditions the mucus is depleted but the ciliary activity is maintained $(8,13)$.

MC was determined by measuring the rate of displacement of an autologous mucus sample placed on the epithelial surface of the mucus-depleted frog palate using a stereoscopic microscope equipped with a reticulated eyepiece. MC was calculated by dividing the distance traveled $(6 \mathrm{~mm})$ by the elapsed time (s). Three measurements were made for each dose and time of the study. The mucus samples were rinsed with petroleum ether to remove the oil prior to their placement on the surface of the palate. The experiments were carried out at room temperature $\left(20^{\circ} \mathrm{C}\right)$. During the measurements the frog palate was maintained inside an acrylic chamber, with a microenvironment of $100 \%$ humidity provided by ultrasonic nebulization of standard Ringer solution mixed with distilled water $(1: 1)(7,8)$.

$\mathrm{CBF}$ was measured by a modification of the videoscopic technique described by Braga (14) by focusing a group of cilia through a light microscope (10X objective, 10X eyepiece) connected to a video camera. The incident light illuminating the ciliated epithelium is reflected from the cilia packed together and from the thin layer of mucus covering the cilia. This reflection is cyclic, because its direction changes according to movements of the underlying cilia. At a certain angle during their stroke, the cilia reflect the incident light into the microscope, and the area of that group of cilia appears as a 
light spot. Some fraction of a second later, the cilia change their angle and the light falls outside the frontal lens of the objective, and this area appears dark. These rhythmic changes of flaring and fading intensity are assumed to represent ciliary activity, and each cycle of light fluctuation corresponds to a beat cycle. The observations using reflected light lead to the measurement of ciliary wave frequency, which is the same as $\mathrm{CBF}$, because if we observe any fixed point on the surface, we see the surface rise and fall at the frequency of the ciliary beat. The other parameter associated with the ciliary wave is the ciliary wavelength, which is a function of the degree of metachronism between neighboring cilia. The activity of the cilia was recorded onto a videotape recorder with the option of slow motion. The CBF was recorded at three locations per test area and counted directly from the screen at slow motion and the real frequency was then calculated (15).

Four groups of frog palates were exposed and monitored for $60 \mathrm{~min}$ after immersion in different solutions as follows: control $(\mathrm{N}=$ 8), standard Ringer solution mixed with distilled water (1:1) and three toxic groups using different concentrations of formaldehyde of $1.25,2.5$ and $5.0 \mathrm{ppm}(\mathrm{N}=10$ for each group). $\mathrm{MC}$ and $\mathrm{CBF}$ were determined at time zero (i.e., before immersion) and then at 15-min intervals.

The values of the relative change of MC and $\mathrm{CBF}$ (MC or $\mathrm{CBF}$ at 15, 30, 45 and 60 min divided by $\mathrm{MC}$ or $\mathrm{CBF}$ at $0 \mathrm{~min}$, i.e., before immersion) were compared among the experimental groups by Kruskal-Wallis one-way analysis of variance using the SPSS version 6.1 statistical program. The level of significance was set at $5 \%$.

Figures 1 and 2 show the relative changes of MC and CBF, respectively. Statistical analysis showed that MC was significantly decreased in the presence of formaldehyde at the concentrations of 2.5 and $5.0 \mathrm{ppm}$ after $60 \mathrm{~min}$ of exposure. $\mathrm{CBF}$ also pre- sented a significant change $(\mathrm{P}<0.05)$ at concentrations of 2.5 and $5.0 \mathrm{ppm}$ when compared to $1.25 \mathrm{ppm}$ of formaldehyde after 60 min of exposure.

The use of biomass fuels for automotive purpose has been considered as a clean alter-

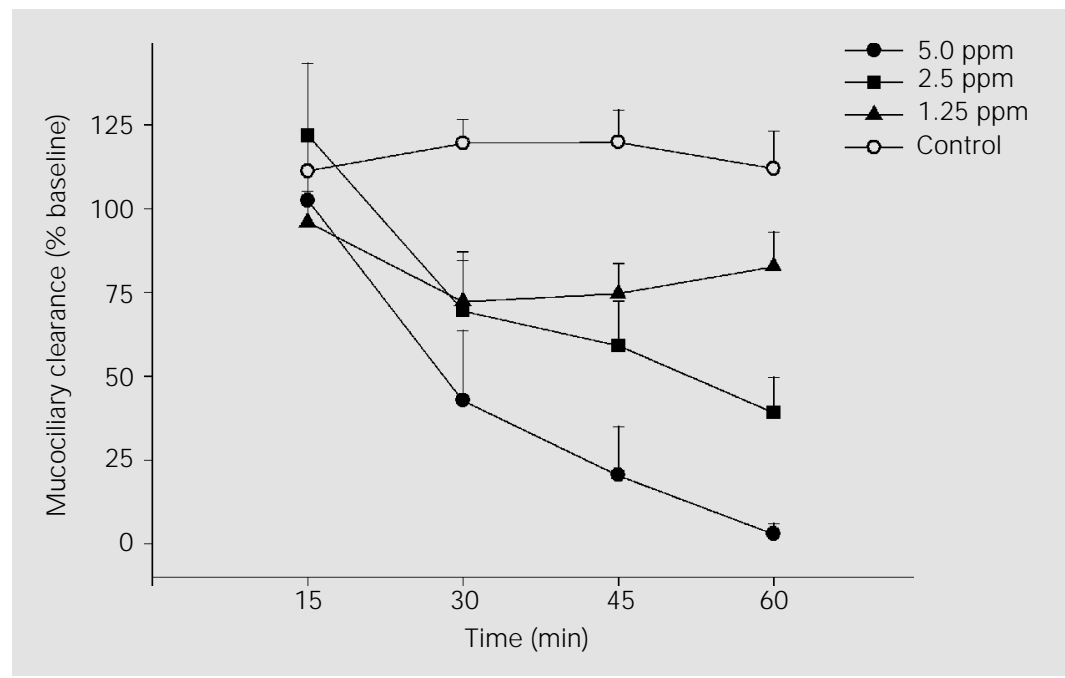

Figure 1 - Mean $( \pm$ SEM ) values of relative change in mucociliary clearance $(M C)$ measured after immersion in Ringer or different concentrations of formaldehyde. The relative changes were obtained by dividing all observations of each assay by the corresponding baseline value. MC decreased significantly in the presence of 2.5 and $5.0 \mathrm{ppm}$ of formaldehyde at 60 $\min (\mathrm{P}<0.05)$.

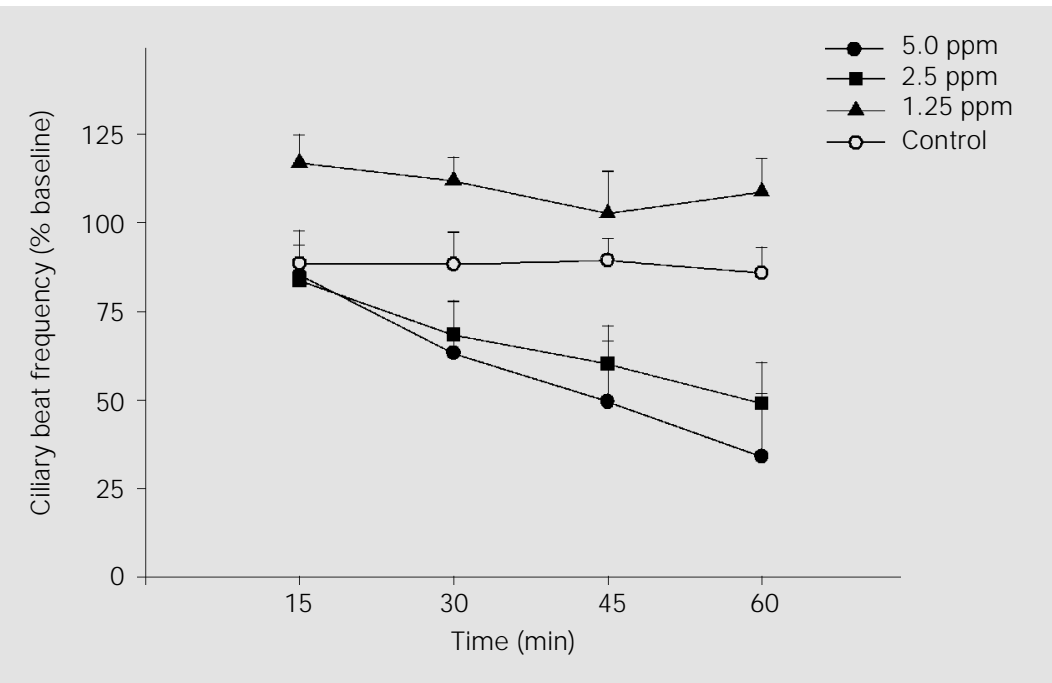

Figure 2 - Mean $( \pm$ SEM ) values of relative change in frog palate ciliary beat frequency $(C B F)$ measured after immersion in Ringer or different concentrations of formaldehyde. The relative changes were obtained by dividing all observations of each assay by the corresponding baseline value. CBF decreased significantly in the presence of 2.5 and $5.0 \mathrm{ppm}$ of formaldehyde compared to $1.25 \mathrm{ppm}$ at $60 \mathrm{~min}(\mathrm{P}<0.05)$. 
native for the increase in air pollution levels recently experienced by large urban centers. In Brazil, the gasoline available for customer's use at service stations routinely contains $22 \%$ of ethanol or methanol. Methanol and ethanol have the potential of being used in large scale energy programs, as occurred in Brazil in the past 20 years. The increment of utilization of alcohol as automotive fuel increases the possibility of individual exposure to aldehydes for short periods of time even in the outdoor environment. Furthermore, formaldehyde is widely used in the plywood industry and in manufacturing of other building materials. The potential of exposure is further aggravated by poor house ventilation that causes accumulation of other air pollutants generated by cigarette smoking, gas cooking, and unventilated household kerosene heaters $(16,17)$. In addition, formaldehyde is still widely employed as tissue fixative in pathology laboratories, creating potential occupational damage for those directly involved in its manipulation. Low concentrations of formaldehyde may cause mild to severe upper airway irritation, depending on the concentration, duration of exposure, and individual susceptibility. These conditions clearly indicate that the problem of exposure to formaldehyde is far from being totally under control and that the proper toxicological evaluation of short-term exposure to low levels of this pollutant is mandatory.

In this study, we utilized the frog palate as a model to assess functional injuries to the mucociliary epithelium. The choice of using the mucociliary system as the toxicological end-point is logical, since it represents the main defense of the lining epithelial layer of the respiratory system, which is the natural interface between the organism and the environment. The same preparation was used by Morgan et al. (18) to study the toxicity of gaseous formaldehyde for mucociliary function, but employing higher concentrations. This epithelium of the frog palate is similar to the airway epithelium of mammals in many aspects, permitting short-term investigations of the toxic effects of substances on ciliary properties such as transport velocity and beat frequency (12). In fact, several in vitro studies concerning the effects of toxic compounds on the ciliated epithelium have been conducted on CBF and mucociliary transport velocity because they play a pivotal role in the transportation of mucus secretions $(5,19,20)$.

The levels of formaldehyde evaluated in the present study were selected taking into account the plausible range of exposure that can be experienced by humans in the indoor environment (16). Our results indicate that formaldehyde affects the ciliated mucosa after short-term exposures and at relatively low concentrations. The adverse effects are dose dependent and are coherently detected by the two estimators of injury employed in this study. The deleterious effects were significant for concentrations of $2.5 \mathrm{ppm}$ or more. Although $1.25 \mathrm{ppm}$ increased CBF when compared to other groups, even to control, MC was impaired. This phenomenon could be due to a toxic effect of the pollutant on the epithelium not leading to harmonic movements of the cilia or to mucus thickness alterations impairing effective mucociliary clearance. On the other hand, our data pointed out that formaldehyde concentrations of $2.5 \mathrm{ppm}$ and higher have a toxic effect, decreasing both $\mathrm{CBF}$ and $\mathrm{MC}$ and leading to mucociliary function impairment.

The present results should be interpreted with caution with respect to their extrapolation to the toxic consequences at equivalent concentrations in the air. Our model of exposure is substantially different from the interaction that occurs between formaldehyde and the ciliary epithelium in breathing conditions. As previously mentioned, formaldehyde is a highly soluble pollutant that is rapidly dissolved in the airway lining fluid. Under these conditions, it is very difficult to 
establish the exact concentration of formaldehyde that is produced in the airway fluid at any given inhaled concentration, since this depends on several variables such as breathing frequency and amplitude, pattern of respiration (nasal vs mouth breathing), amount of periciliary fluid and effectiveness of mucus removal. Although our system of exposure allows a precise definition of the exposure dose, it does not reflect the conditions that exist during tidal breathing. This limitation is also present in other studies of in vitro exposure to gaseous pollutants.

In summary, our study provides evidence that relatively low concentrations of formal- dehyde are sufficient to cause mucociliary impairment. These results suggest that some degree of ciliary stimulation is observed even at $1.25 \mathrm{ppm}$, a lower dose than the Brazilian threshold limit value established as tolerable. Thus, our results show that formaldehyde impairs mucociliary function at levels within the range that may be found in some indoor environments. In addition, we corroborated the findings of Morgan et al. (18) supporting the concept that the frog palate is a useful, simple and low-cost preparation to assess the effects of formaldehyde on mucociliary clearance.

\section{References}

1. Watson AT, Bates RR \& Kennedy D (1988). Air Pollution, the Automobile, and Public Health. National Academy Press, Washington, DC.

2. International Agency for Research on Cancer (IARC) (1985). Allyl compounds, aldehydes, epoxides and peroxides. Carcinogenesis risks on humans. IARC Monography Evaluation.

3. Grafström RC (1990). In vitro studies of aldehyde effects that relate to human respiratory carcinogenesis. Mutation Research, 238: 175-184.

4. Feron VJ, Til HP, de Vrijer F, Woutersen RA, Cassee FR \& van Bladeren PJ (1991). Aldehydes: occurrence, carcinogenic potential, mechanism of action and risk assessment. Mutation Research, 259: 363385.

5. Dalhamn T (1956). Mucous flow and ciliary activity in the trachea of healthy rats and rats exposed to respiratory irritant gases $\left(\mathrm{SO}_{2}, \mathrm{H}_{3} \mathrm{~N}, \mathrm{HCHO}\right)$. A functional and morphologic (light microscopic and electron microscopic) study, with special reference to technique. Acta Physiologica Scandinavica, 36: 151-161.

6. Sadé J, Eliezer N, Silberberg A \& Nevo AC (1970). The role of mucus in transport by cilia. American Review of Respiratory Disease, 102: 48-52.

7. Lorenzi G, Böhm GM, Guimarães ET, Costa Vaz MA, King M \& Saldiva PHN (1992). Correlation between rheologic properties and in vitro ciliary transport of rat nasal mucus. Biorheology, 29: 433440.

8. Macchione M, Guimarães ET, Saldiva PHN \& Lorenzi-Filho G (1995). Methods for studying respiratory mucus and mucus clearance. Brazilian J ournal of Medical and Biological Research, 28: 13471355.

9. Wanner A, Salathé $M \&$ O'Riordan TG (1996). Mucociliary clearance in the airways. American J oumal of Respiratory and Critical Care Medicine, 154: 18681902.

10. Vesilind PA, Pierce J J \& Weiner RF (1990). Solid and hazardous waste law. In: Vesilind PA, Pierce JJ \& Weiner RF (Editors), Environmental Pollution and Control. 3rd edn. Butterworth-Heinemann, Boston, 231-266.

11. Brain JD (1970). The uptake of inhaled gases by the nose. Annals of Otology, Rhinology and Laryngology, 79: 529-539.

12. Macchione $M$, Lorenzi-Filho $G$, Guimarães ET, J unqueira VBC \& Saldiva PHN (1998). The use of the frog palate preparation to assess the effects of oxidants on ciliated epithelium. Free Radical Biology and Medicine, 24: 714-721.

13. Rubin BK, Ramires O \& King M (1990). Mucus-depleted frog palate as a model for the study of mucociliary clearance. J ournal of Applied Physiology, 69: 424429.
14. Braga PC (1988). In vivo observation and counting methods for ciliary motion. In: Braga PC \& Allegra L (Editors), Methods in Bronchial Mucology. Raven Press, New York, 269-276.

15. Festa E, Guimarães E, Macchione $M$ Saldiva PHN \& King M (1997). Acute effects of uridine 5 '-triphosphate on mucociliary clearance in frog palate. J ournal of Aerosol Medicine, 10: 25-39.

16. Harris MO \& Spoo W (1997). Toxicological Profile for Formaldehyde. Agency for Toxic Substances and Disease Registry, Department of Human and Health Services, Bethesda, MD, USA.

17. Repace J L \& Lowrey AH (1980). Indoor air pollution, tobacco smoke, and public health. Science, 208: 464-472.

18. Morgan KT, Patterson DL \& Gross E (1984). Frog palate mucociliary apparatus; structure, function and response to formaldehyde gas. Fundamental and Applied Toxicology, 4: 58-68.

19. Gerde P, Muggenburg BA, Sabourin PJ , Harkema J R, Hotchkiss J A, Hoover MD \& Henderson RF (1993). Disposition of polycyclic aromatic hydrocarbons in the respiratory tract of the beagle dog. Toxicology and Applied Pharmacology, 121: 319-327.

20. Gemity TR, Bennett WD, Kehrl H \& DeWitt PJ (1993). Mucociliary clearance of inhaled particles measured at $2 \mathrm{~h}$ after ozone exposure in humans. J ournal of Applied Physiology, 74: 2984-2989. 